\title{
DC electric pump modified as an intelligent actuator
}

Bomba elétrica de corrente contínua modificada como um atuador inteligente

Bomba eléctrica DC modificada como un actuador inteligente

\section{Alex Esteban Barbosa Torres ${ }^{1}$ Andrés Escobar Díaz ${ }^{2}$ Harold Vacca Gonzalez ${ }^{3}$}

Received: January $14^{\text {th }}, 2019$

Accepted: March $28^{\text {th }}, 2019$

Available: May $28^{\text {th }}, 2019$

How to cite this article: A. E. Barbosa, A.E. Díaz, H. Vacca González, "DC electric pump modified as an intelligent actuator", Revista Ingeniería

Solidaria, vol. 15, n. ${ }^{\circ} 2,2019$.

DOI: https://doi.org/10.16925/2357-6014.2019.02.06

Artículo de investigación. https://doi.org/10.16925/2357-6014.2019.02.06

1 Universidad Distrital Francisco José de Calda, Bogotá. Colombia.

ORCID: https://orcid.org/0000-0001-9547-0600

E-mail: aebarbosat@correo.udistrital.edu.co

2 Universidad Distrital Francisco José de Caldas (UDFJ de C), Colombia. Científico (CIDC)

de la UDFJ de $C$.

ORCID: https://orcid.org/0000-0003-0527-8776

3 Universidad Distrital Francisco José de Caldas (UDFJ de C), Colombia.

ORCID: https://orcid.org/0000-0001-7017-0070 


\section{Abstract}

Introduction: This paper describes the research - developed in 2007 by ORCA and SciBas - that modifies an actuator device (AD) - DC electric pump - making it Smart.

Problem: There are currently no intelligent ADs of open architecture with the possibility of being easily manipulated in didactic plants.

Objective: To identify and implement circuits to control an AD with signals.

Methodology: The AD is developed following the family-standard IEEE 1452: implementing communication interfaces that characterize intelligent transducers connected to systems based on microprocessors, instruments and networks. The integration is made in a configuration platform that displays, records and manipulates $A D$ information through a PC.

Results: Obtaining a low-cost system based on Raspberry Pi - as an intelligent core - where the following are integrated: a PSOC 4 microcontroller to interact with the signals of the actuator, a circuit to manage the energy between the pump and the microcontroller, and an integrated signal that goes to a processor

Originality: Modify a DC electric pump -as part of a didactic plant system- to have an intelligent AD architecture. The checking of filling and flow rates indicate advantages over traditional instrumentation: noise immunity, effective isolation of circuits from sources, work sequences, effective storage of actuator information, simple calibration, ease of signal transmission and remote control, and the possibility of intelligent presentations.

Limitations: In non-didactic plants it is necessary to extend the research to the industrial sector and increase the quality of the elements.

Keywords: Direct Current Electric pump, hydraulic actuator, intelligent actuator, microprocessor, microcontroller.

\section{Resumen}

Introducción: El presente artículo describe la investigación -desarrollada en 2017 por ORCA y SciBas- que modifica un dispositivo actuador (DA) - electrobomba DC- haciéndolo inteligente.

Problema: No se tiene un DA inteligente de arquitectura abierta con la posibilidad de ser manipulado sencillamente en plantas didácticas.

Objetivo: identificar e implementar circuitos para controlar un DA con una señal.

Metodología: EI DA se desarrolla cumpliendo la familia-norma IEEE 1451. Implementa interfaces de comunicación que caracterizan transductores inteligentes conectados a sistemas basados en microprocesadores, instrumentos y redes. La integración se realiza en una plataforma de configuración que visualiza, registra y manipula información del DA a través de un PC.

Resultados: Obtención de sistema de bajo costo basado en Raspberry Pi -como núcleo inteligente-donde se integra: un microcontrolador PSOC 4 para interactuar con las señales del actuador, un circuito para manejar la energía entre la bomba y el microcontrolador, y una señal integrada que va a un procesador.

Originalidad: Modificar una electrobomba DC - como parte de un sistema de una planta didáctica- para que tenga una arquitectura de DA inteligente. La comprobación de tasas de llenado y caudal indican ventajas respecto a la instrumentación tradicional: inmunidad al ruido, aislamiento efectivo de los circuitos a las fuentes, secuencias de trabajo, almacenamiento efectivo de la información del actuador, calibración simple, facilidad en la transmisión de señales y en el control remoto, y posibilidad de presentaciones inteligentes. Limitaciones: En plantas no didácticas se requiere ampliar la investigación al sector industrial e incrementar la calidad de los elementos.

Palabras clave: electrobomba de corriente directa, Actuador hidráulico, Actuador Inteligente, microprocesador, microcontrolador. 


\section{Resumo}

Introdução: este trabalho descreve a pesquisa, desenvolvida em 2007 pelo ORCA e SciBas, que modifica um dispositivo atuador (DA) - bomba elétrica de corrente contínua - e o torna inteligente.

Problema: atualmente, não existem DAs inteligentes de arquitetura aberta com a possibilidade de serem facilmente manipulados em plantas didáticas.

Objetivo: identificar e implementar circuitos para controlar um DA com sinais.

Metodologia: o DA é desenvolvido de acordo com os padrões IEEE 1452: implantando interfaces de comunicação que caracterizam transdutores inteligentes conectados a sistemas estabelecidos em microprocessadores, instrumentos e redes. A integração é feita em uma plataforma de configuração que exibe, grava e manipula informações do DA através de um computador.

Resultados: obter um sistema de baixo custo baseado no Raspberry Pi - como centro de inteligência - em que está integrado o seguinte: um microcontrolador PSOC 4 para interagir com os sinais do atuador, um circuito para gerenciar a energia entre a bomba e o microcontrolador e um sinal integrado que leva a um processador.

Originalidade: modificar uma bomba elétrica de corrente contínua - como parte do sistema de uma planta didática - para chegar a uma arquitetura de DA inteligente. A revisão das taxas de abastecimento e do fluxo indica vantagens sobre a instrumentação tradicional: imunidade a ruídos, isolamento efetivo que separa os circuitos das fontes, sequências de trabalho, armazenamento efetivo de informações do atuador, calibração simples, facilidade da transmissão de sinal e controle remoto e a possibilidade de apresentações inteligentes.

Limitações: em plantas não didáticas, é necessário estender a pesquisa para o setor industrial e aumentar a qualidade dos elementos.

Palavras-chave: bomba elétrica de corrente contínua, atuador hidráulico, atuador inteligente, microprocessador, microcontrolador.

\section{Introduction}

Hydraulic actuators - pumps and electric pumps- [2], are devices that transform electromechanical energy into hydraulic energy, [3]. This is obtained by doing work to keep a liquid moving, so that increasing the energy of the fluid increases its pressure or kinetic energy. For example: in a centrifuge, the impeller creates a suction current at the inlet of the pump introducing the fluid inside it and pushing it towards the hydraulic circuit - volute- [4] where, due to the effect of the centrifugal force, the fluid is driven to the outlet or outlet nozzle [5], [6]. The selection of such a pump will depend on basic variables such as flow rate, relative elevation and volume [6], see Figure 1. Taking into account its operation, this type of actuator can be found in almost any application related to fluids -from small to large scale- since they are robust elements. When analyzing these applications it can be observed, regardless as to whether it is a pump, motor pump, or electric pump, that its purpose and principles of operation are the same, despite the fact that the origin of the energy transferred to the fluid is different. However, hydraulic pumps are machines that transform the mechanical energy with which they are driven into energy for the fluid they move. The fluid can be a 
liquid or a mixture of liquids and solids -concrete, for example-; in general, a pump los used to increase the pressure of a liquid by adding energy to the hydraulic system to move the fluid from one area to another; Therefore, the need to provide intelligence to these actuators is a current problem due to the concurrence of all the energy transformations that occur.
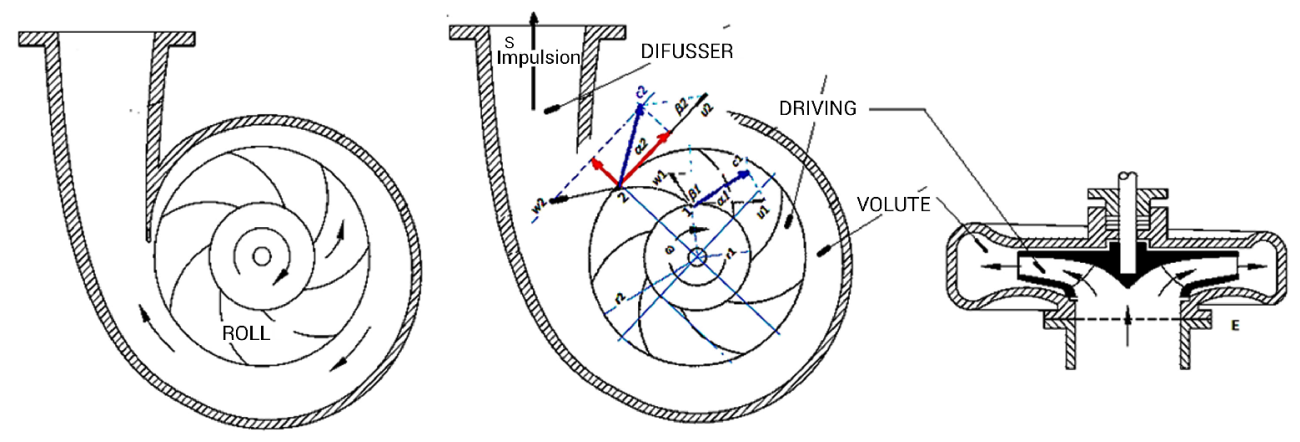

Figure 1. Configuration and Triangles of speeds of a Centrifugal hydraulic pump Source: own work adapted from [7]

Among the recent research that has led to the development and implementation of intelligent actuators -based on IEEE 1451 and using Arduino with the Raspberry PI-, is a ball valve operated by means of a servo motor [8] but communication was made only through the SSH protocol. In [9], a level control system for a water pump tank and thermal energy storage in washing and dyeing processes -similar to [8] but a more high-end device- was developed. In [10], the real-time implementation of a controller for an intelligent actuator was developed using a transducer with the ability to monitor, but this technology was applied in the field of medicine. In [11], a methodology was proposed to monitor and control the flow of liquid in the pipeline of industries through a web server via a controlled solenoid valve.

However, under the focus of the previous investigations, in this article, ORCA and SciBas document the one that led to the modification of a DC electric pump -as part of a didactic plant system - so that it has an intelligent actuator architecture.

Its structure is as follows: initially, in the materials and methods section, according to the guidelines of the IEEE 1451 standard, the characteristics of the development of an intelligent actuator are established and its application for electric pump is specified by mathematical and physical models. A succinct description is then given of some classes of electric pumps, different power circuits commonly used for the activation of DC motors - applicable to electric pumps- and control by modulation of pulse width PWM. 
Then the experimental implementation of the basic actuator system in an intelligent actuator architecture is described. Next, the results of the verification of the filling and flow rates of the plant - via digital signal- at different useful cycles of the controller are presented and discussed. Finally, the conclusions are presented.

\section{Materials and methods}

An intelligent AD is guaranteed when its standard operation - after modeling - complies with the IEEE 1451 standard family guidelines. It defines a set of communication interfaces that characterize intelligent transducers connected to microprocessor, instrument and network-based systems. First, the architecture is defined: a Network Capable Application Processor (NCAP) and a Transducer Interface Module (TIM), in addition to the interface between both.

For the NCAP, hardware and software whose objective is to provide a gateway between the different TIMs and the user network have been considered. To control the TIM a digital interface is structured.

For the TIM, transducers are designed -using conversion electronics and signal processing- and data sheets called Transducer Electronic Data Sheets (TEDS) are generated, and an IEEE 1451.X communication module refers to the physical interface between the TIM and the NCAP.

Regarding the TEDS, when containing information of the transducer identification, the measurement range or calibration data is established.

To access the NCAP, the user network and the HTTP protocol are adapted -as it appears in the IEEE 1451.0 standard, and 1451.1, 1451.2, and 1451.3-.

By supplying the characteristics of an intelligent actuator and its subsystems: sensors, power, data processing, transmission measurement, external communication, and human operational communication, its operation is verified through a filling test of the plant at different useful cycles of the controller via digital signal.

\subsection{Mathematical model in Hydraulic Pumps}

In the idea of establishing the general operation of a pump, the mathematical modeling of speeds, relative heights and torque of the motor is convenient, particularly when considering the centrifuges (see Figure 2). 

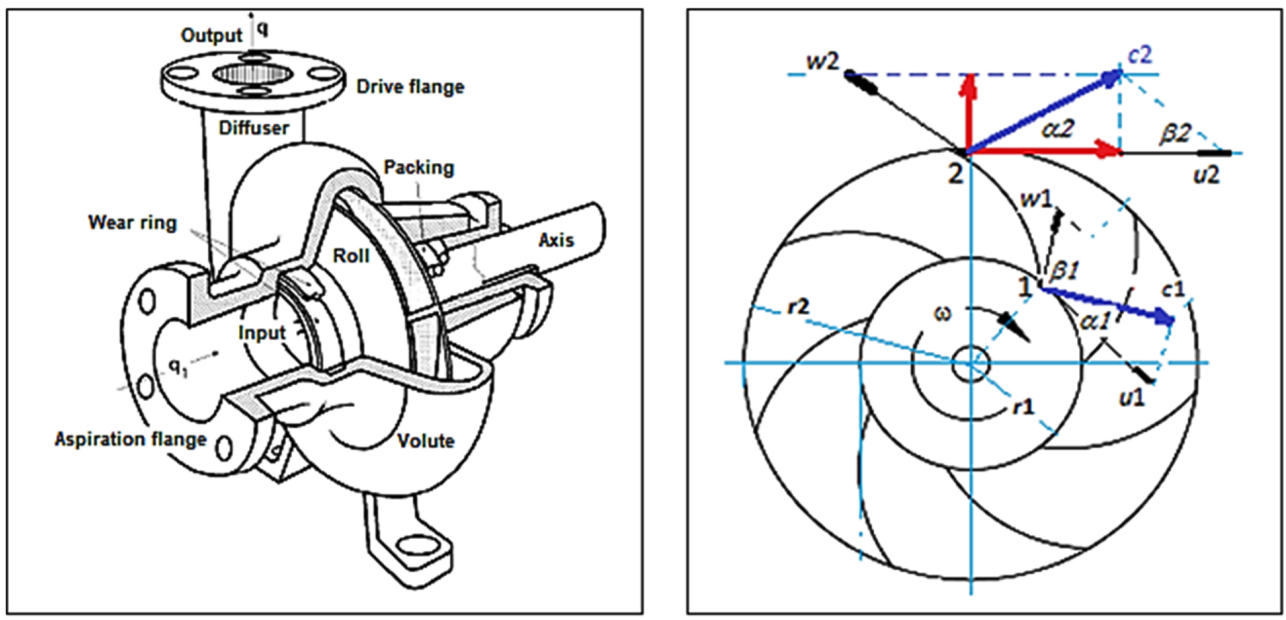

Figure 2. Centrifugal pump, layout, scheme and perspective, [8]; speed triangles in impeller, suitable for [7].

Source: own work adapted from [20]

The main component is the impeller, which in Figure 2 can be seen with the blades arranged according to a section perpendicular to the axis of the pump. The flow arrives at the impeller through a conduit perpendicular to it -in a direction normal to the plane of the figure - axial direction-, and changes to the radial direction crossing the space or channel delimited between the vanes. The liquid is subjected to a relative velocity ' $w$ ' as it passes through the space between the blades - between the inlet and the outlet-, and at a dragging speed ' $u$ ' due to the rotation of the impeller about the axis. The vector sum of these velocities provides the absolute velocity ' $c$ '. It should be noted that the fluid enters the impeller without energy and comes out with pressure energy ' $P S / \gamma$ ' and with kinetic energy ' $c 2 S / 2 g$ '. Outside the impeller, it will become pressure energy in the volute, which will cause losses; it is assumed that the ' $c S$ ' velocities are small.

According to Figure 2, if ' $w 1$ ' is called the relative speed of the liquid at the entrance to the chamber - delimited by a pair of blades-, ' $u 1$ ' the tangential speed of drag, and ' $c 1$ ' the absolute speed, the triangle of speeds at the entrance is obtained. At the exit of the impeller there is another triangle of speeds determined by: the relative speed, ' $w 2$ '; tangential velocity, ' $u 2$ '; and the absolute speed, ' $c 2$ '. If ' $H$ ' is the difference between the minimum and maximum level of the liquid; ' $\mathrm{Ha}$ ' is the height or level of aspiration, -height between the axis of the pump and the lower level of the liquid-; and ' $H i$ ' is the driving height, - height between the impeller shaft and the upper level of the liquid-. These variables can be used to obtain (1):

$$
H=H a+H i
$$


The theoretical suction height for an infinite number of vanes and operating the pump under ideal conditions would be equivalent to the water column corresponding to the pressure at its lowest level; however, this height is always lower because it is necessary to take into account:

- $\quad$ - Load losses in the pipe

- $\quad$ - Friction at the entrance of the impeller

- $\quad$ - Temperature of the liquid to be raised

- $\quad$ - Cavitation phenomenon

Considering the Bernoulli equations for the drive flange and the suction flange

The Bernoulli equation for impulsion is: $c 2 S / 2 g+p S / \gamma+z S$

The Bernoulli equation for aspiration is: $\mathrm{c} 2 E / 2 g+p E / \gamma+z E$

And from the difference between (2) and (3), the manometric height created by the pump is obtained -the difference between the distances ' $\mathrm{zS}$ ' and ' $\mathrm{zE}$ ' is negligible- . Put simply, the power applied by the motor to the pump shaft depends on the torque and the angular speed of the pump; the manometric height is the total height created by the pump multiplied by the manometric performance. The expression then remains in terms of absolute velocities, tangential velocities, and cosines of the angles ' $\alpha 1$ ' and ' $\alpha 2$ '. Consequently, for a given impeller and angular speed of rotation ' $\omega$ ', the lifting height achieved by the pump is independent of the pumped liquid; that is to say, a pump with a certain impeller and rotating at a predetermined rotation speed would achieve equal elevation, pumping, for example, two liquids of different density. If it is taken into account that, for two columns of liquid of the same height, the heaviest liquid will correspond to the densest liquid. The denser the liquid, the greater the pressure at the outlet of the pump - delivery flange-, therefore resulting in a greater energy consumption. Therefore, a variation in the density of the pumped liquid influences and modifies the pressure in the delivery flange, as well as the power to be applied to the pump [12]. 


\subsection{Types of hydraulic pumps according to the operating principle}

\subsubsection{Pumps of positive or volumetric displacement}

The principle of operation is based on hydrostatics [13]; so that the increase of pressure is made by the push of the walls of the chambers that vary their volume. In this type of pumps, the impeller positively generates a given volume or displacement, which is why they are also called volumetric pumps. In the case of a pump being able to vary the maximum volume of displacement, it is called a variable volume pump. If that volume cannot be varied, then it is said that the pump is of fixed volume [4].

There are two types:

- Reciprocating pumps: as represented in Figure 3, in which there is one or more fixed compartments, but of variable volume, caused by the action of a piston or a membrane. In these machines, the movement of the fluid is discontinuous and the processes of loading and unloading are carried out by valves that open and close alternately. Some examples of this type of pumps are the reciprocating piston pump, the rotary piston pump or the axially operated piston pump.

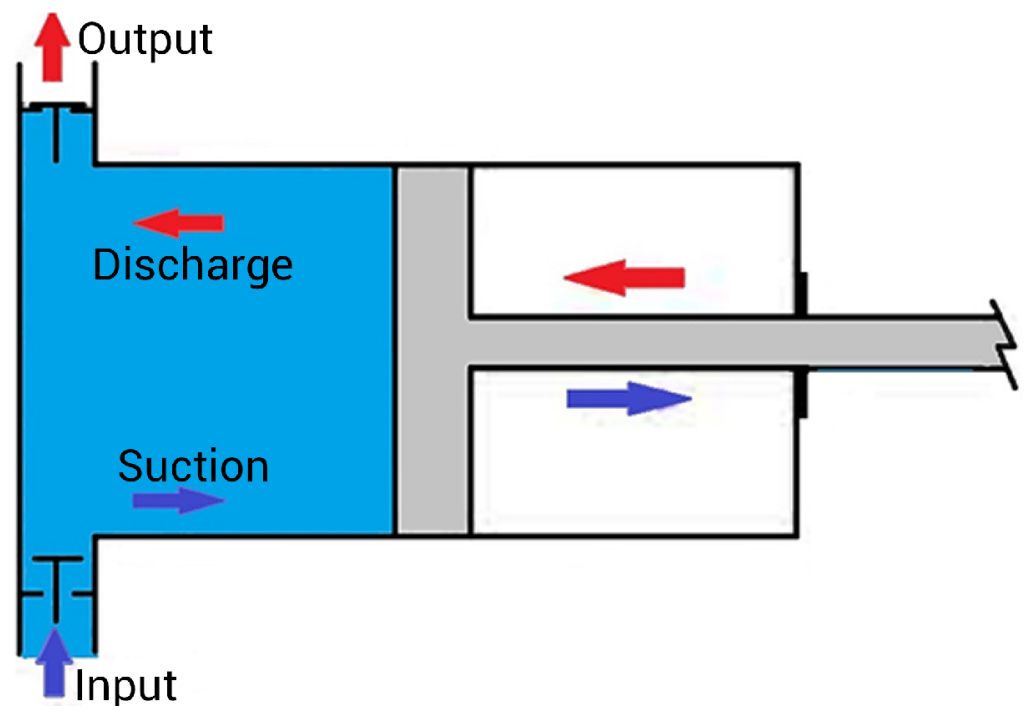

Figure 3. Positive displacement pump - reciprocal diagram Source: [14] 
- Rotating pumps: in which a fluid mass is confined to one or several compartments that move from the entrance area -low pressure- to the exit zone - high pressure - of the machine. Some examples of this type of machine are the vane pump, the lobe pump, the gear pump, the screw pump or the peristaltic pump. Some of the most used pumps are:

- Vane pumps: generally have lower plates of circular shape, Figure 4. A slotted rotor is fixed to an axis that enters the cavity of the cover through one of the external plates. A number of small rectangular plates or vanes are fixed within the rotor slots. As the rotor rotates, the centrifugal force causes the outer edge of each blade to slide along the surface of the cavity of the shell, while the blades slip in and out of the rotor slots. At the moment when the cavities become large, they take the fluid sucked by the inlet nozzle and when they become small, they discharge the liquid through the outlet nozzle.

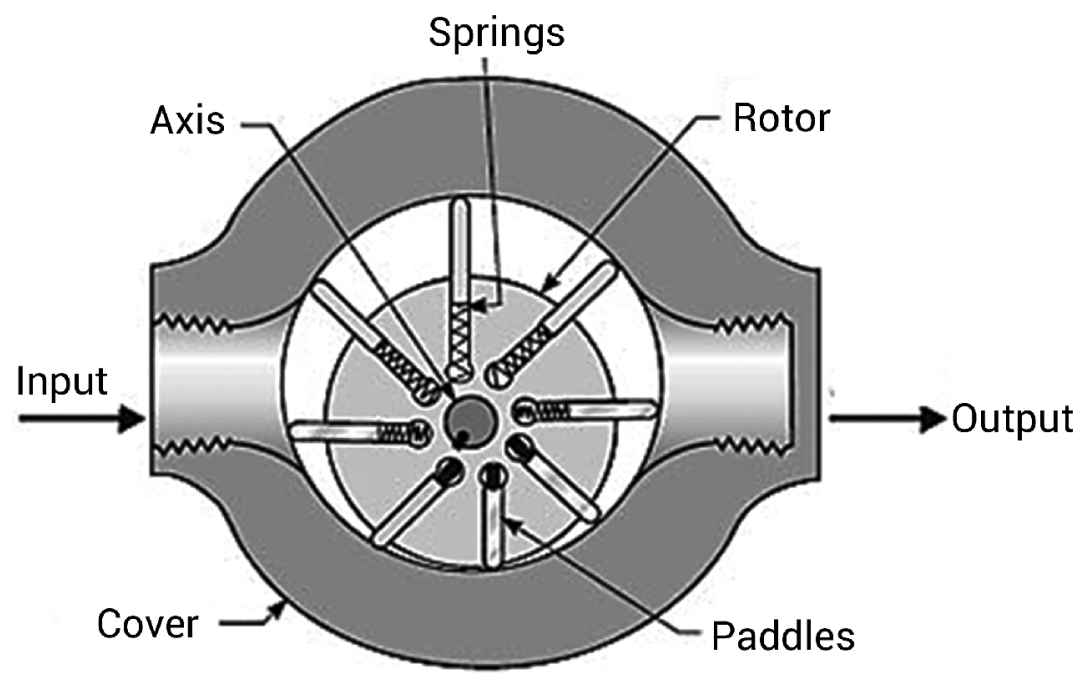

Figure 4. Rotary vane pump diagram Source: [15]

- Gear Pump: consists of an internal gear and an external gear, Figure 5. The internal gear has one tooth less than the external gear. The shape of the tooth of each gear is related to that of the other in such a way that each tooth of the internal gear is always in contact with the surface of the external gear. This movement generates pockets which transport the fluid when increasing in size and unload the fluid when decreasing in size. 

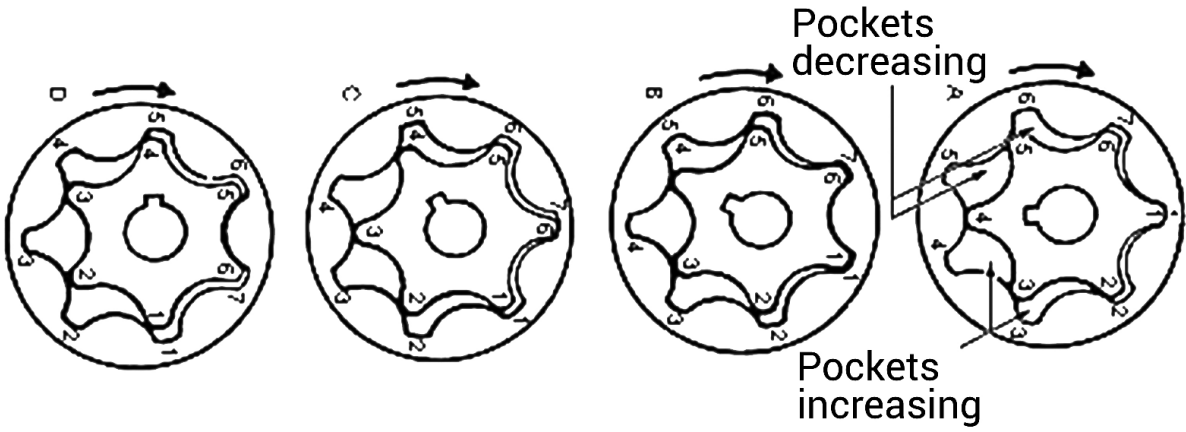

Figure 5. Rotary gear pump diagram Source: [15]

- Lobe pumps: follow a similar principle to that of the gear pump, that is, both lobes turn in the opposite direction (see Figure 6), which increases the volume and decreases the pressure to get the fluid suction [15].

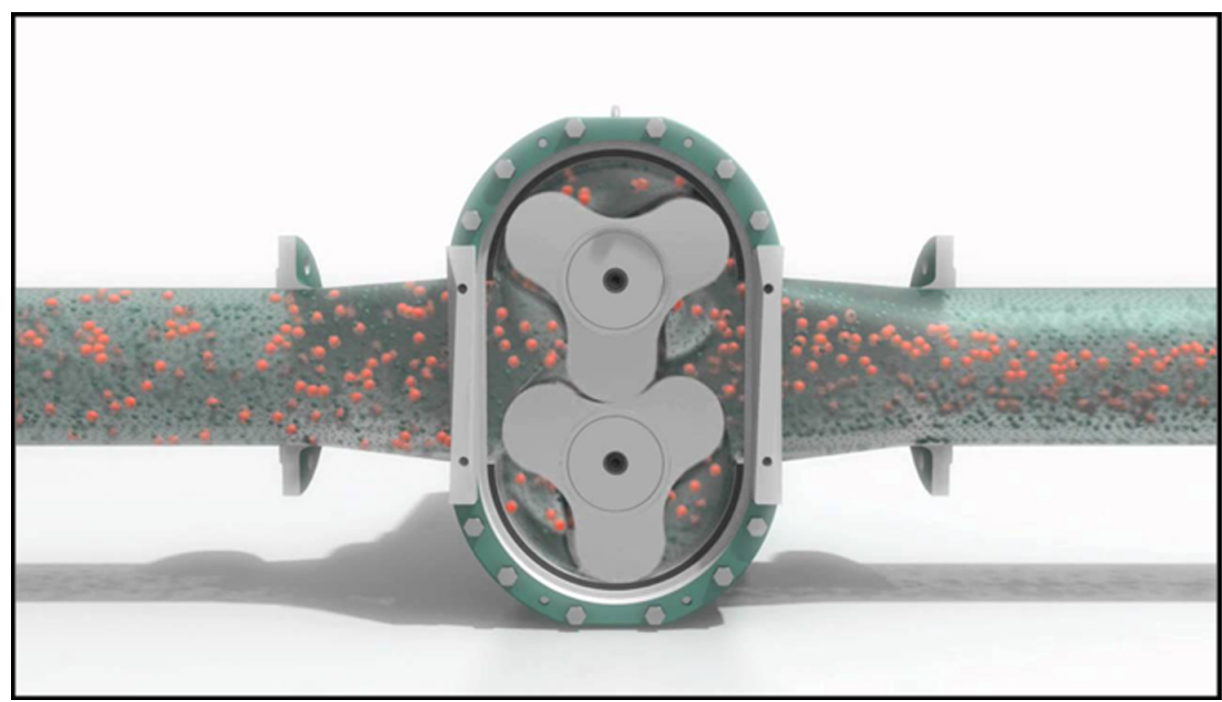

Figure 6. Rotary lobe pump Source: [16]

\subsubsection{Rotodynamic pumps}

The principle of operation is based on the exchange of momentum between the machine and the fluid, applying hydrodynamics. In this type of pump there are one or several impellers with rotating blades generating a field of pressures in the fluid. In this type of machine the fluid flow is continuous, [4]. These hydraulic, turbomachine generators can be subdivided into: 
- $\quad$ Radial or centrifugal, already seen in the modeling section [5], [6].

- Axial, Figure 7, where the fluid passes through the channels of the blades following a trajectory contained in a cylinder.

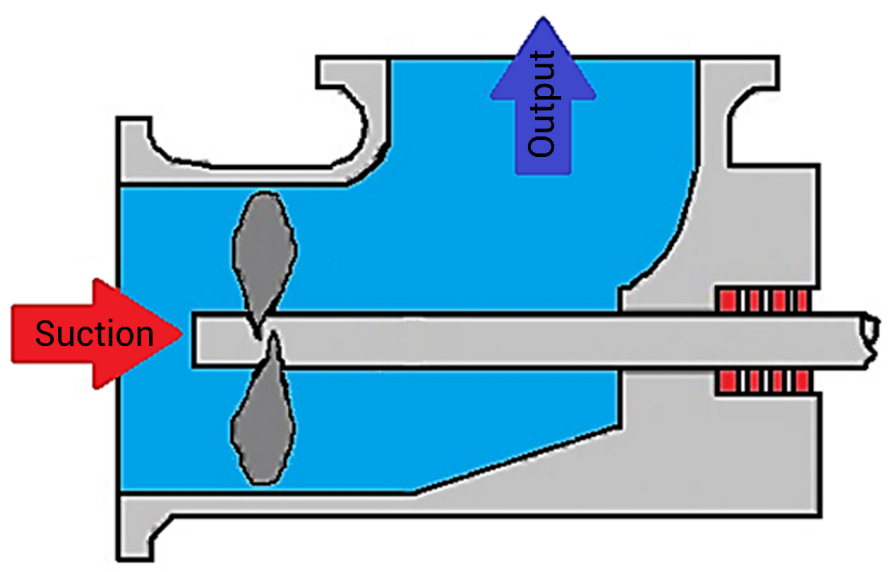

Figure 7. Operating diagram of an axial rotodynamic pump Source: [17]

- Diagonal or Helicocentrifugal pumps are centrifugal pumps that instead of having a circular impeller have a shape such that the liquid in its interior, instead of turning completely radial to the axis of rotation of the impeller, does so obliquely, Figure 8.

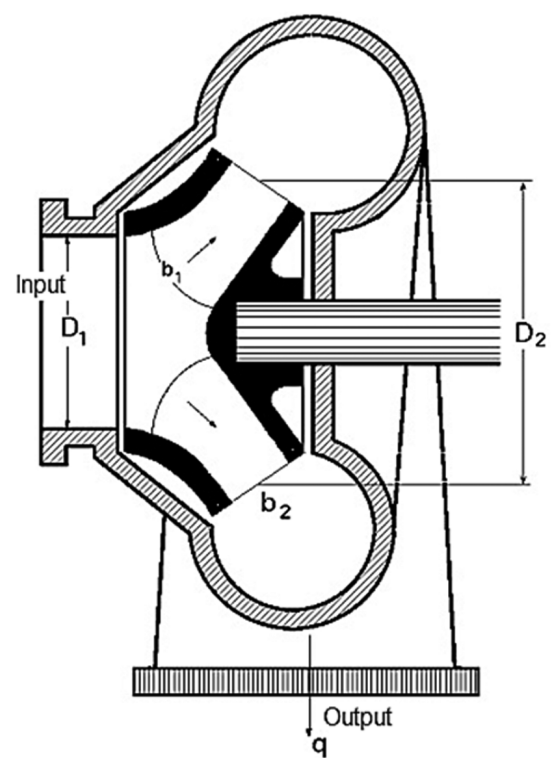

Figure 8. Outline of a Helicocentrifugal pump Source: [18] 


\subsubsection{Electric pumps}

Electric pumps are devices that fulfill the same function of a motor pump but with the distinction that the electric pump works with an electric motor -it can be DC or ACthat gives movement to the rotor blades [19]. There are two types of electric pumps, the first is the electric pump with through-shaft and the second is the electric pump with magnetic coupling.

\subsubsection{Transverse Shaft Electric Pumps}

It is basically the same operation of a common electric motor but with the difference that the shaft is coupled to the end of the vanes that are responsible for transporting the fluid through the hydraulic circuit, [6]. That is to say, in comparison with the conventional motor pumps that give movement to the shaft with an internal combustion engine, in this case the movement of said axis occurs due to the operation of an electric motor, Figure 9.

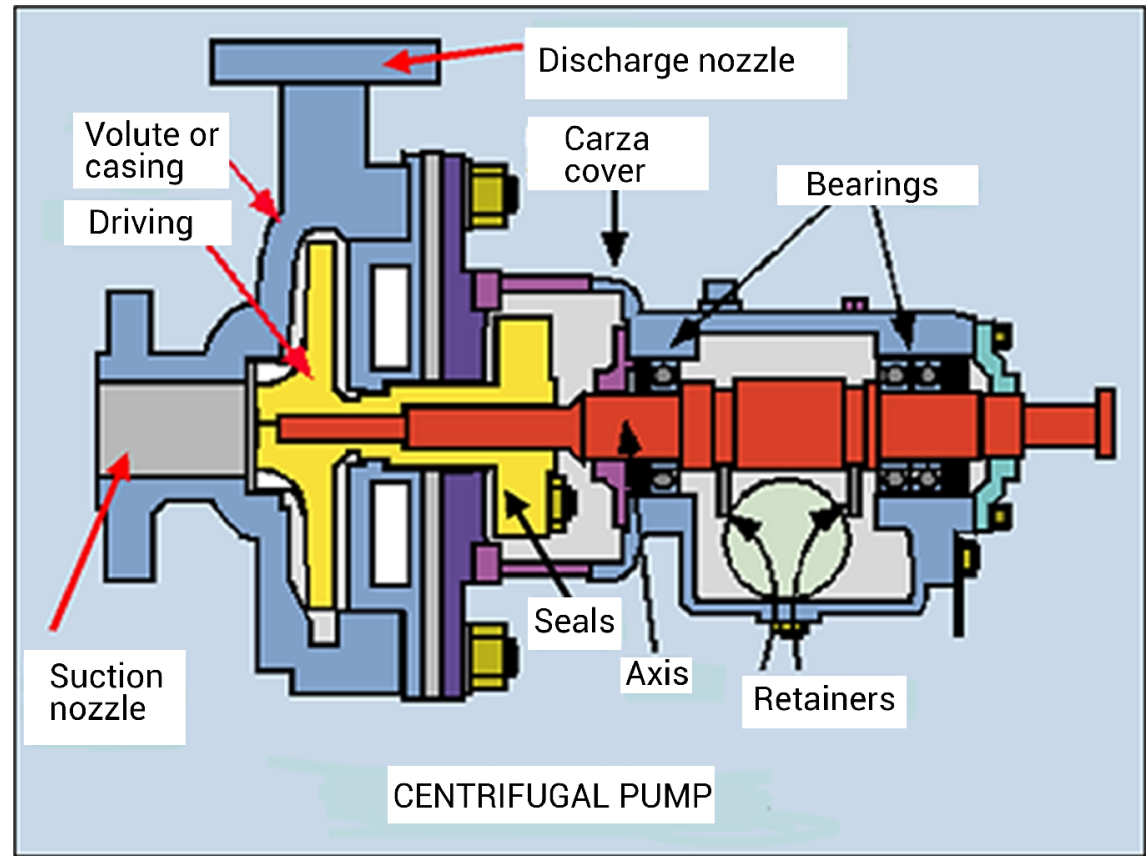

Figure 9. Parts of a transverse shaft electric pump Source: [20] 


\subsubsection{Magnetic Coupler Electric Pump}

It is a system of power transmission of a drive motor to an axis using magnetic forces. Such forces are achieved by a couple of sets of permanent magnets. Figure 10 shows the schematic of a magnetic coupling pump. Two sets of permanent magnets are used. One of them is rigidly attached to the drive shaft and is called the drive magnet. Its counterpart is the driven magnet and is integral to the pump impeller. The magnetic forces of attraction and repulsion that exist between both magnets are strong enough to transmit the power of the motor to the pump impeller [6].

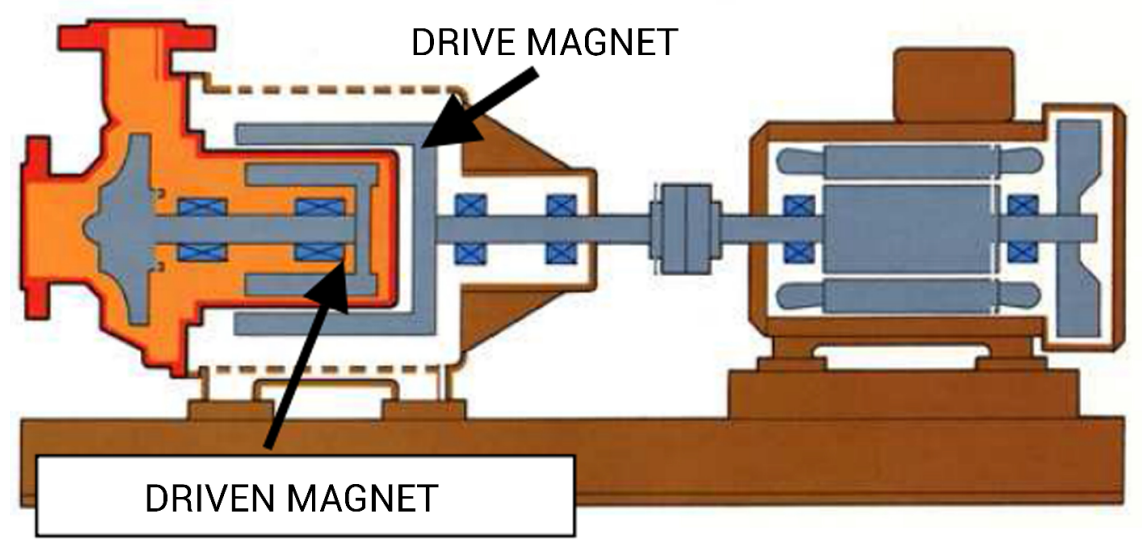

Figure 10. Schematic of a magnetic coupling Source: [21]

\subsection{Power circuits for $\mathrm{DC}$ motors}

Power circuits are responsible for executing the orders given by the control circuit -command-, providing the necessary power to meet the needs of that task. A specific example for the use of these circuits can be the variation of speed of a DC motor with a PWM signal - control signal most frequently used for this task- for its control. Some circuits commonly used to provide the power to DC motors are:

- $\quad$ PWM circuits for DC motor power

The principle of operation of these circuits, Figures 11 and 12, is the switching controlled between ON and OFF of the voltage that is supplied to the motor. This is achieved with PWM signals and different combinations of dedicated semiconductors providing the required power. 


\section{- $\quad$ Power circuit with PROFET and PWM}

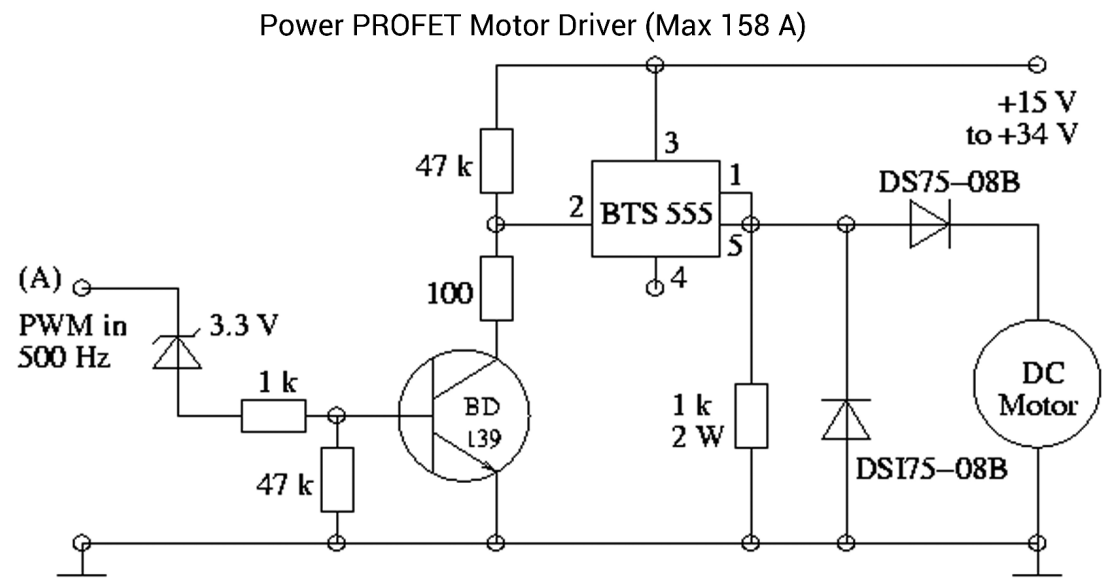

Figure 11. Power circuit with PROFET and PWM Source: [22]

- Driver for motor with Power MOSFET and PWM

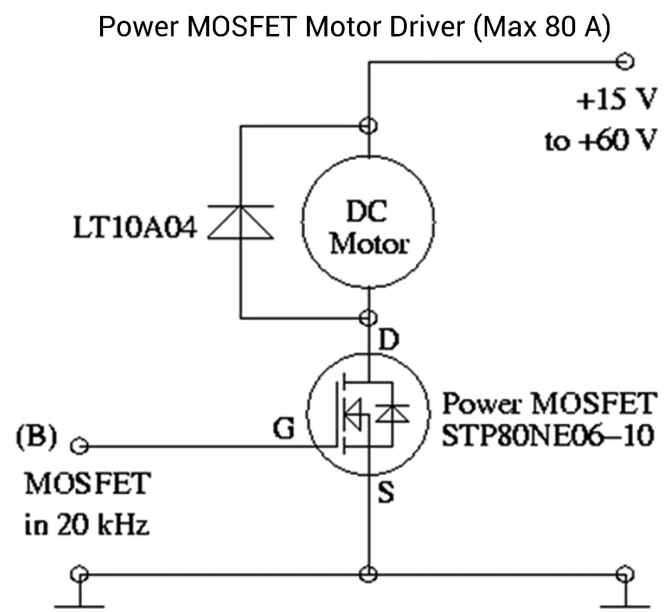

Figure 12. Driver for motor with Power MOSFET and PWM

Source: [22]

\section{- $\quad$ H bridge, Figure 13.}

It consists of an arrangement with switching devices that are configured in pairs in such a way that when a pair is switched ON, a circuit is established with a direction of current input from + to - from one of the tips of the motor windings, to change the direction of rotation of the motor, the torque with the current direction opposite to the previous one is turned ON. 


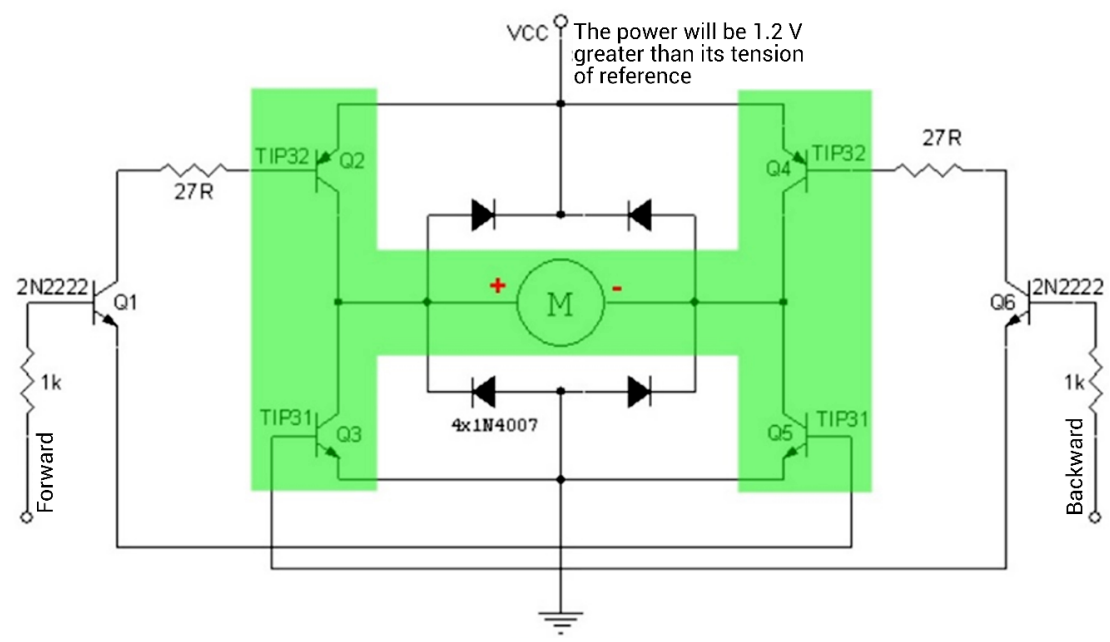

Figure 13. $\mathrm{H}$ bridge circuit

Source: [23]

- Integrated Circuit Drivers

- L293, Figure 14.

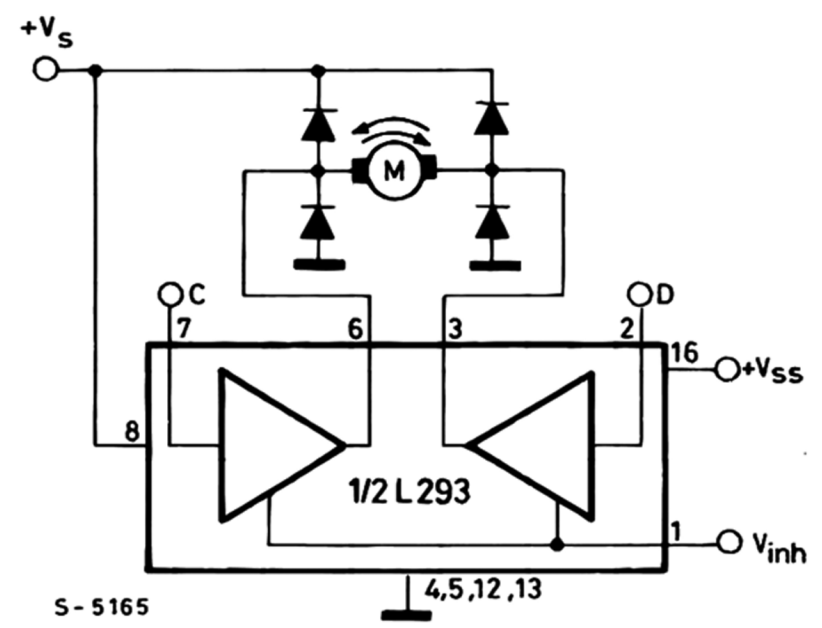

Figure 14. Power circuit control direction of a DC motor Source: [24]

The integrated L293D includes four circuits to handle medium power loads, especially small motors and inductive loads, with the ability to control current up to $600 \mathrm{~mA}$ in each circuit and a voltage between $4.5 \mathrm{~V}$ to $36 \mathrm{~V}$. But also, any of these four circuits serve to configure the half of an $\mathrm{H}$ bridge. The integrated one therefore allows for the formation of two complete $\mathrm{H}$ bridges, [25]. 
ULN2003, Figure 15.

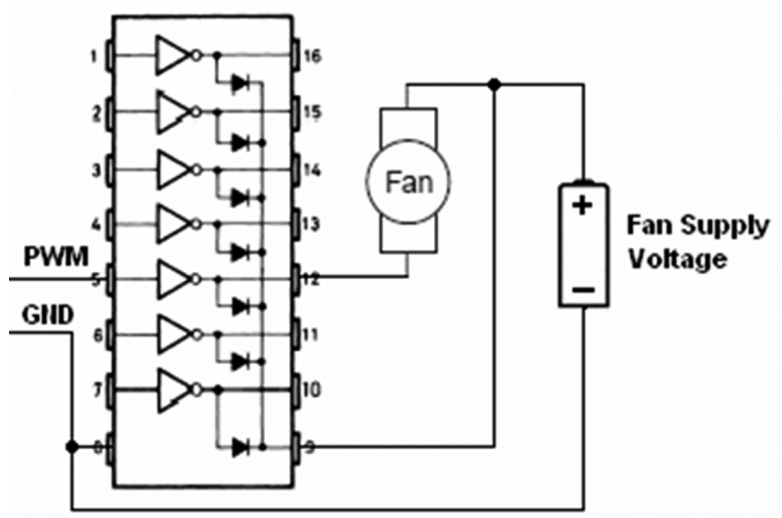

Figure 15. Power control circuit speed of a DC motor with ULN2003 Source: [26]

ULN2003 integrated circuits are an array of 7 pairs of PNP Darlington transistors with common cathode, high voltage output. Its most common use is to control DC motor power; step by step. [27]

- $\quad$ Used power circuit, Figure 16.

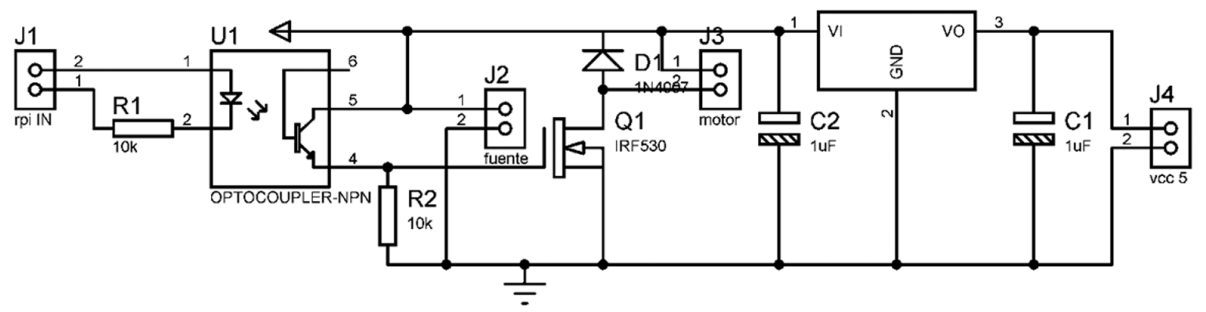

Figure 16. Power Circuit.

Source: own work.

To supply the energy needs of the system, a driver is designed whose function is to protect the development card on any eventual short or unwanted currents. The signal that is used to control the speed of the actuator is a pulse width modulation PWM that goes from 0 to $3.3 \mathrm{v}$-the maximum voltage that the GPIO pins can deliver-. As the output current of the GPIO pins of the Raspberry pi is not sufficient for the operation of the pump, a MOSFET transistor is implemented to take the current from an external power supply to meet the needs of the pump. To ensure that the necessary current is drawn from the external power supply and not from the Raspberry pi, an 
optocoupler is used to isolate the two voltages. Additionally, to protect the MOSFET, a diode is included in parallel with the brushes of the motor. This is done because when the circuit stops, the rotor continues to rotate due to its inertia and generates a magnetic field that affects the transistor. The function of the diode is to serve as a return for the excess energy in the coil or brushes, for its total dissipation.

\subsection{Pulse Width Modulation (PWM), control signal}

Pulse width modulation (PWM) is a technique in which the work cycle of a periodic signal -typically sinusoidal or square - is modified to transmit information through a communications channel, or to control the energy that is sent to a load. In this sense, it consists of providing energy in the form of pulses and not continuously.

This demodulation type generates a digital signal formed by square waves of the same frequency, in which the part of the period in which the signal is active is varied. Figures 17-21 show graphs with different useful cycles with a voltage of $5 \mathrm{~V}$ $(V p)$, where the period is the time taken to repeat the cycle and the useful cycle, the time for which the signal is active, [28].

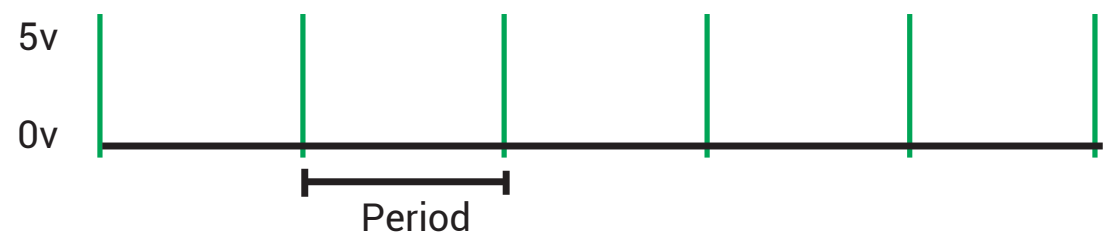

Figure 17. PWM signal with useful cycle of $0 \%$ Source: [28]

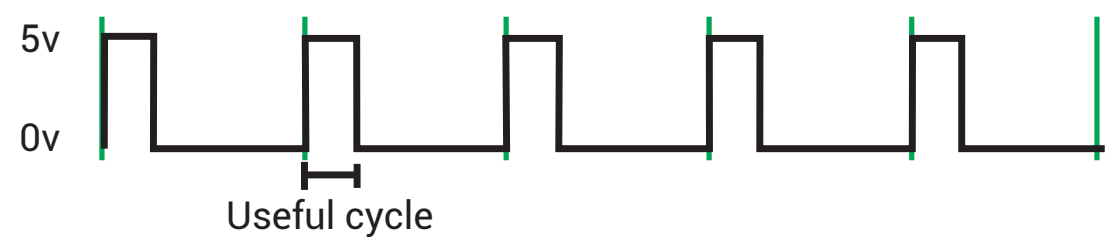

Figura 18. PWM signal with useful cycle of $25 \%$ Source: [28]

As can be seen in Figure 18, there is a signal with a voltage $\mathrm{Vp}=5 \mathrm{~V}$ and a useful cycle of $25 \%$ which is equivalent to a voltage $V m=V p * 0.25$ equivalent to $V m=1.25 \mathrm{~V}$. 


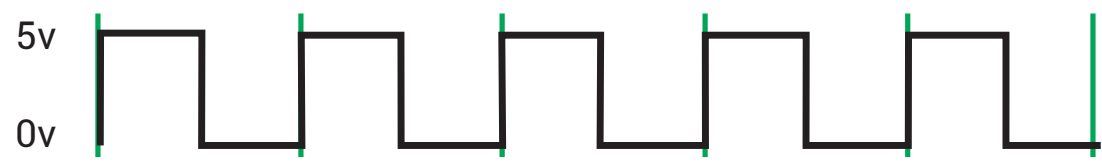

Figure 19. PWM signal with useful cycle of $50 \%$

Source: [28]

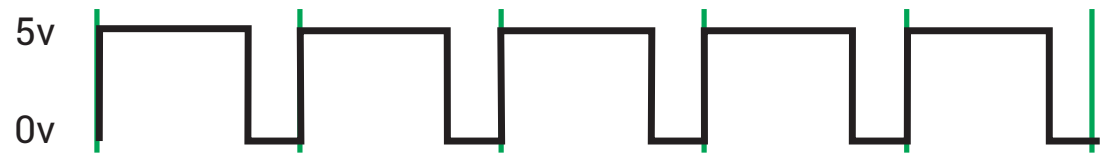

Figure 20. PWM signal with useful cycle of $75 \%$.

Source: [28]

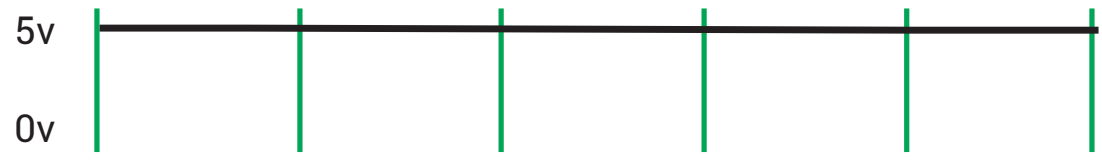

Figure 21. PWM signal with useful cycle of $100 \%$

Source: [28]

This is an efficient way to vary the speed and power of electric DC motors. These controllers can be used, for example to vary the speed of small electric vehicles, control the speed of hydraulic pumps or other motor applications.

Therefore, the best switching conditions are when the switching frequency is much higher than the motor dynamics. The motor must "think" that it is powered by a certain DC voltage. Due to the different references the frequency must be at least five times higher than the rotation speed of the motor. For example, if the motor rotates at $6000 \mathrm{rpm}$ (100 rps) the frequency should be higher than $5 * 100 \mathrm{~Hz}=500 \mathrm{~Hz}$, [29].

\section{Experimental assembly: Basic Actuator System}

As can be seen in Figure 22, the general scheme of operation of the actuated components consists in varying the flow rate of the electric pump by means of a PWM input signal to the power circuit, which in turn is in charge of supplying power to the electric pump. 


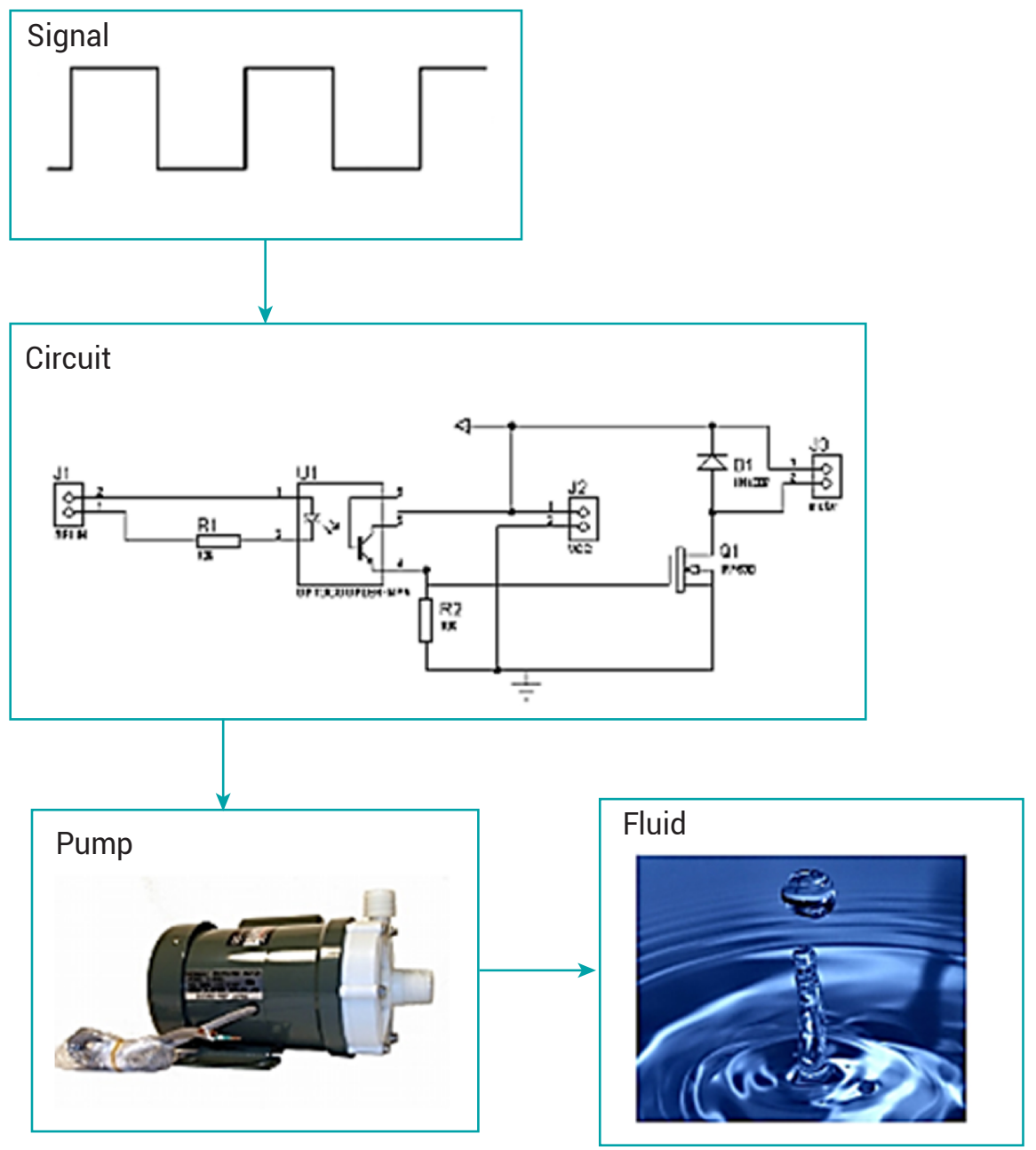

Figure 22. Basic diagram of the operation of the electric pump in the device. Source: own work.

As can be seen in Figure 23, a PWM signal is generated by the PSoC 4. With this, the flow rate of the electric pump, Figure 24, will be controlled by means of a power circuit that deals with the variation of the useful cycle of the signal PWM as a variation of equivalent power that transports the fluid from one tank to the other. 


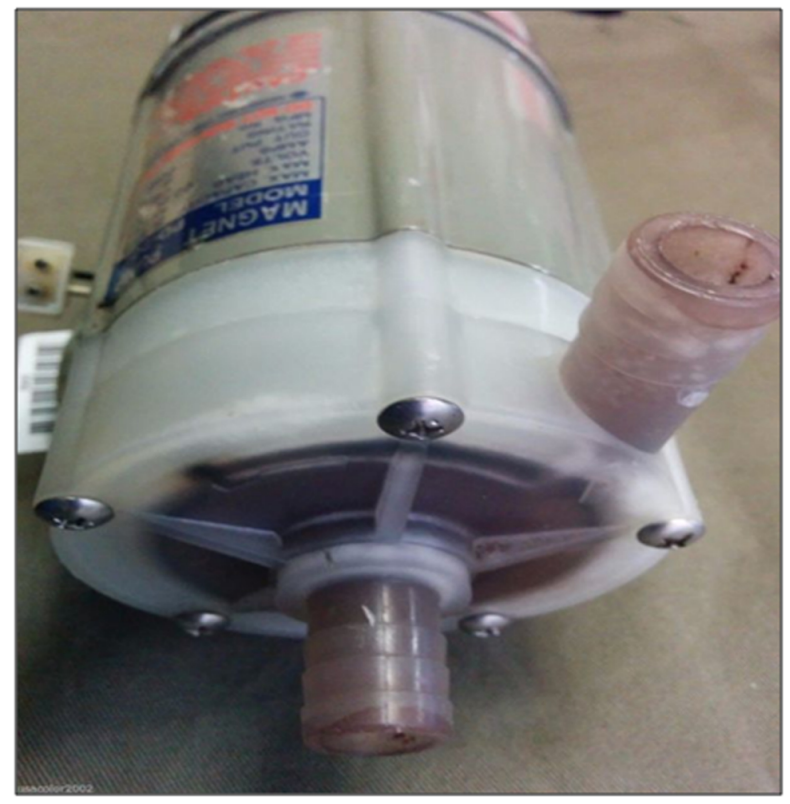

Figure 23. Magnetic coupling electric pump used. Source: own work.

\subsection{General characteristics of the Noritsu Koki PD-20 electric pump, Figure 23.}

It is an industrial magnetic coupling electric pump, with a maximum flow of: 24 liters/minute, operating voltage: 24 Volts DC; rated current: 1.4 Amps; max power: 33.6 Watts; pump type: diaphragm (magnetic coupling).

\subsection{List of actuator module components}

For the Development Systems: Raspberry pi B +; PSoC 4; and NI-USB 6008 Actuator: Noritsu Koki magnetic coupling pump PD-20

Power circuit: 4n25 optocoupler; MOSFET type N IRF 530; resistors of values: 330 Ohms, 10kOhms; 1 uf capacitors

Miscellaneous: switching power supply from $24 \mathrm{~V}$ to $5 \mathrm{~A}$; switched power supply from $5 \mathrm{~V}$ to 20A; ethernet-wifi modem with cable; Power cables; custom case for raspberry pi and PSoC 4; Multi-tank structure for project integration. 


\section{Implementation of the basic actuator system in an intelligent actuator architecture}

According to Figure 24, the development of an actuator for hydraulic systems leads to an instrument for the control of the flow rate of an actuator (electric pump) belonging to a multi-tank system, in such a way that the user has the facility to vary said magnitude digitally and analogously by means of two user interfaces designed for the Java PC and Labview ${ }^{\circledR}$, Figure 25.

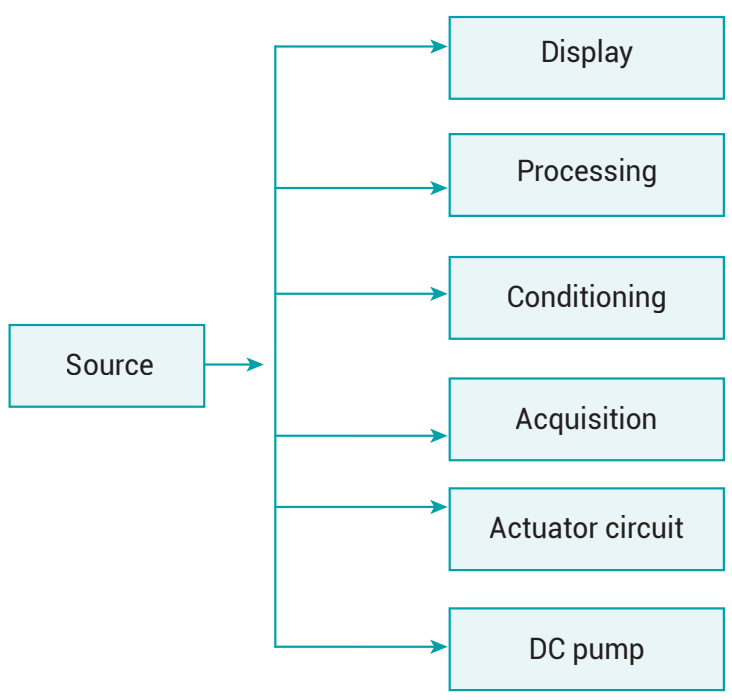

Figure 24. Block diagram of an Actuator for hydraulic systems.

Source: own work. 


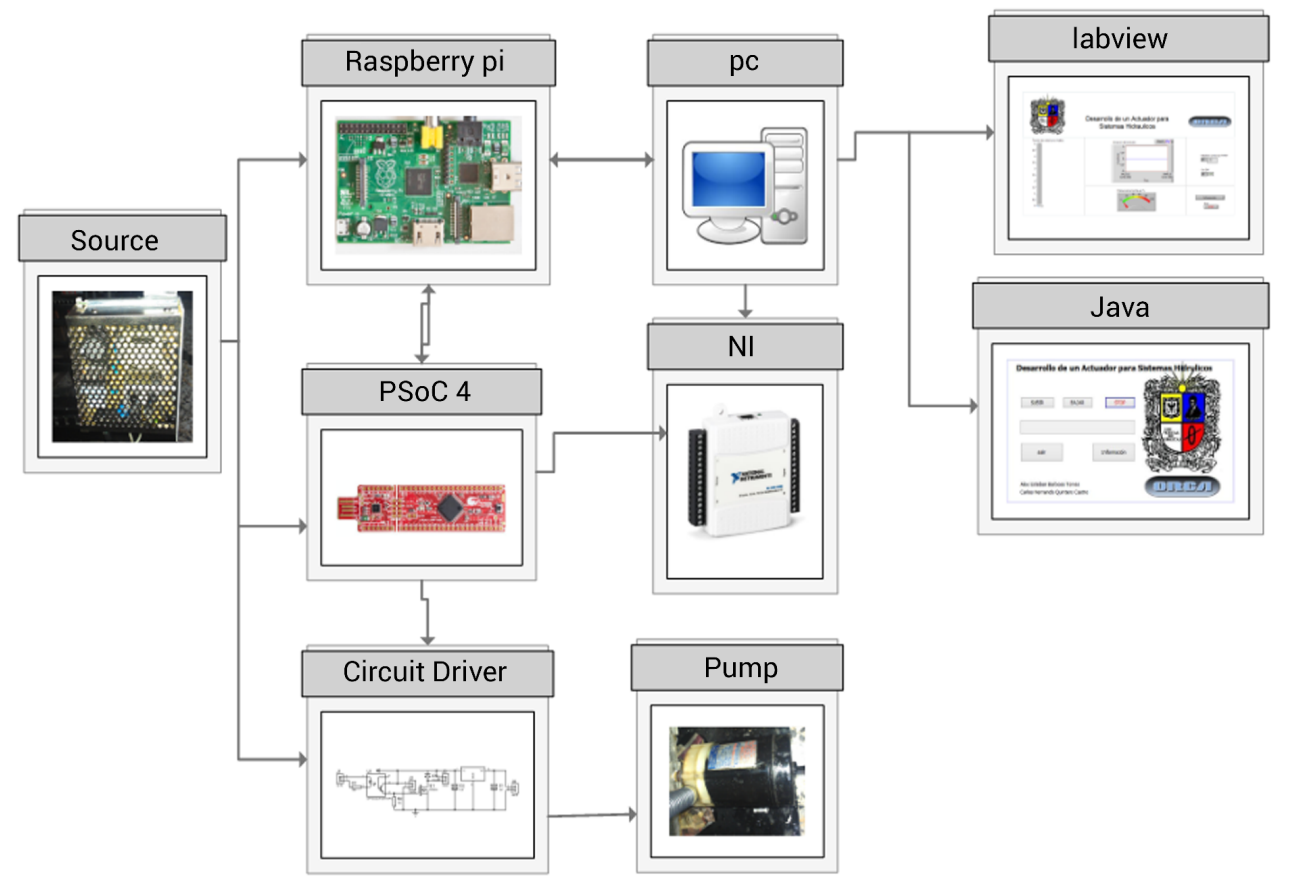

Figure 25. Block diagram as a whole.

Source: own work.

Figures 26 and 27 show the parallels between the architecture ruled by the standard and the intelligent actuator proposed in functional block diagram.

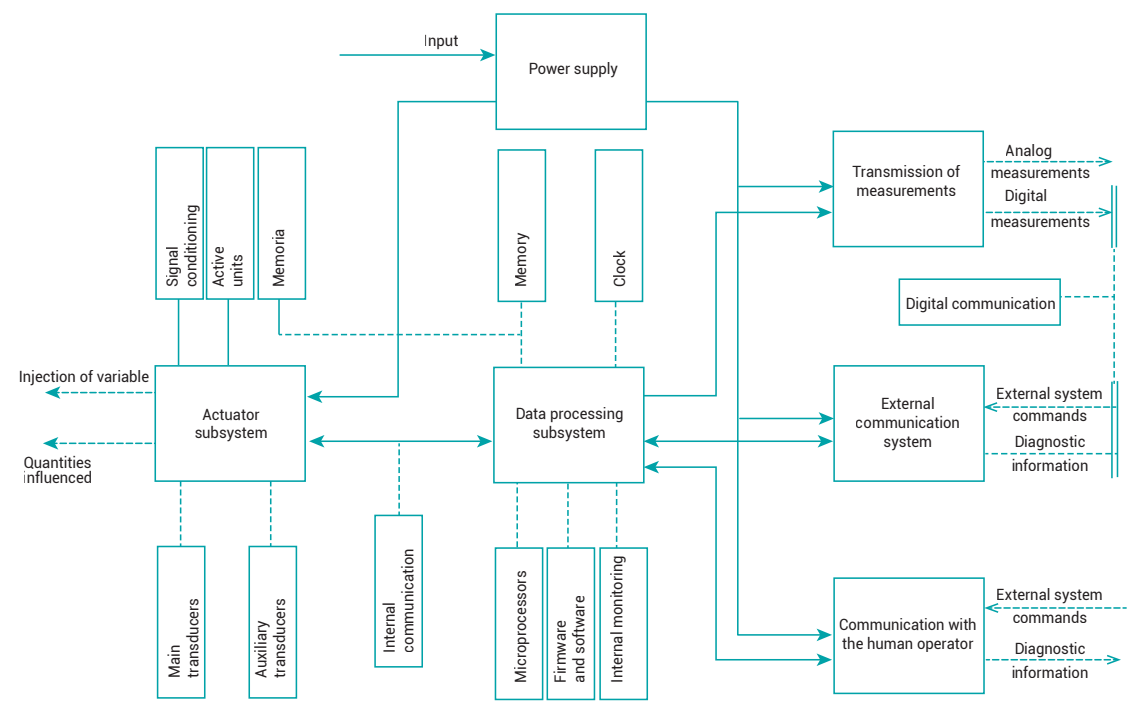

Figure 26. Architecture of an intelligent actuator Source: [30] 


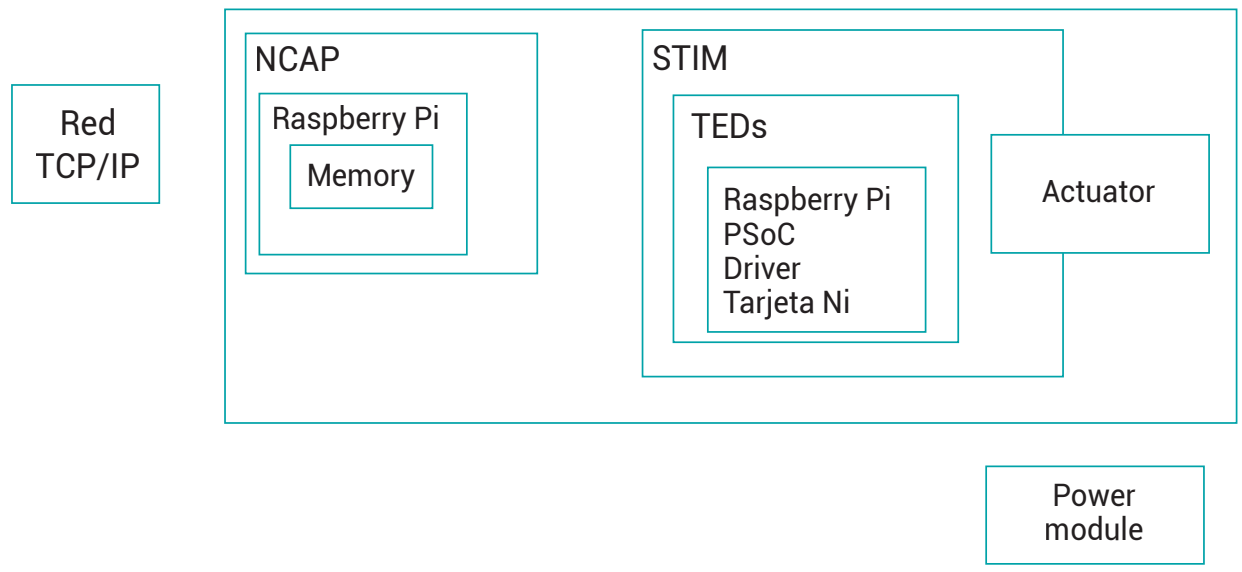

Figure 27. Intelligent actuator in the executed project block diagram. Source: own work.

As established by the IEEE 1451 standard, all the features and modules to be taken into account are verified so that a device is considered an Intelligent Actuator. These modules are:

- TCP/IP network: communication protocol responsible for the transmission of data between the user interface and actuator. This is achieved through the implementation of a Raspberry Pi microprocessor. This development card was used for its interconnection characteristics between a computer network and other development cards as an expansion.

- NCAP: data conversion between the user interface and the actuator through TCP / IP communication. It consists of a set of commands stored in the application and also in the non-volatile memory of the Raspberry Pi that can then be read by the microprocessor. These data are sent and received in a char type format that is compatible with the application software and the microprocessor.

- $\quad$ TIM: interface of the transducer module - actuator - that contains one or more transducers, conversion electronics, signal processing and TEDS; in this block, PSoc 4 and NI-USB development cards are implemented. The PSoc 4 is used as a card expansion of analog ports of the Raspberry Pi development card. This is achieved through the i2c communication established in the IEEE 1451.2, IEEE 1451.3 and IEEE 1451.4 standards in order to interconnect a transducer analogous to a latest technology microprocessor. Also noteworthy is the implementation of the NI-USB development 
card. This card gives the ability to control -analogously- by means of voltage the electric pump through the analog / digital conversion (ADC) ports of the PSoc 4 card.

- TEDS: disposition of the characteristic information of each device integrated to the interface and stored in a non-volatile memory. These features are housed in Java and Labview ${ }^{\circledR}$ applications and can also be found in the non-volatile memory of raspberry development cards Pi and PSoc 4, [31].

- Power module: separated from the other functional blocks in case of failure thus preventing damage to the development cards, the power circuit of the electric pump or the actuator. This power module's main characteristic is as a switched source that provides greater rigidity and current stability.

- Source: a 24 Volt DC to 3 A source is included for the actuator requirements. This voltage is regulated to power the other development cards. This source is robust with good protection against shorts, surges and electromagnetic fluctuations.

- Raspberry Pi: development card that is in charge of controlling, taking data and sending them to different types of communication device. This card alone does not meet the requirements of the actuator module and so, to mitigate this failure, a PSoC 4 is integrated as a port expansion card.

- PSoC 4: development card that aims to control the actuator and the same time take the data sent by the National Instruments card. For this, it is necessary to connect through the i2c protocol to the Raspberry Pi so that it can capture the values and vary the Pulse Width Modulation (PWM) of the analog port.

- NI data acquisition card: development card that controls the speed of the pump by means of voltage magnitudes from the Labview ${ }^{\circledR}$ software. This value sent by the $\mathrm{NI}$ card is captured by the PSoC 4.

- Computer: through Ethernet communication, the speed of the pump is controlled from web applications or java. When the user modifies values in the different stages of the device, this value is recognized by the Raspberry Pi development card and this in turn processes that information to then be sent to PSoC 4 and thus control the DC pump. It must also be able to create a local network for the interconnection of other modules and thus work together for the integration of the multi-tank system.

- Electric pump: an actuator that by means of the power circuit is responsible for supplying the liquid for the other modules. This actuator is a centrifugal DC magnetic coupling pump whose characteristics allow the actuator to 
transport different liquids without damaging the pump, being able to move up to 24 liters/minute to a height of 4.1 meters, making it possible to send the liquid to relatively high places.

\section{Tests and results}

The results were obtained from the filling test of the plant at different useful cycles of the controller through the digital signal for checking the filling and flow rates. For verification of the flow rate of the pump, the calibrated SFI-800-1 / 2 sensor was used for the visualization of the flow variable.

\section{Useful cycle Vs Time}

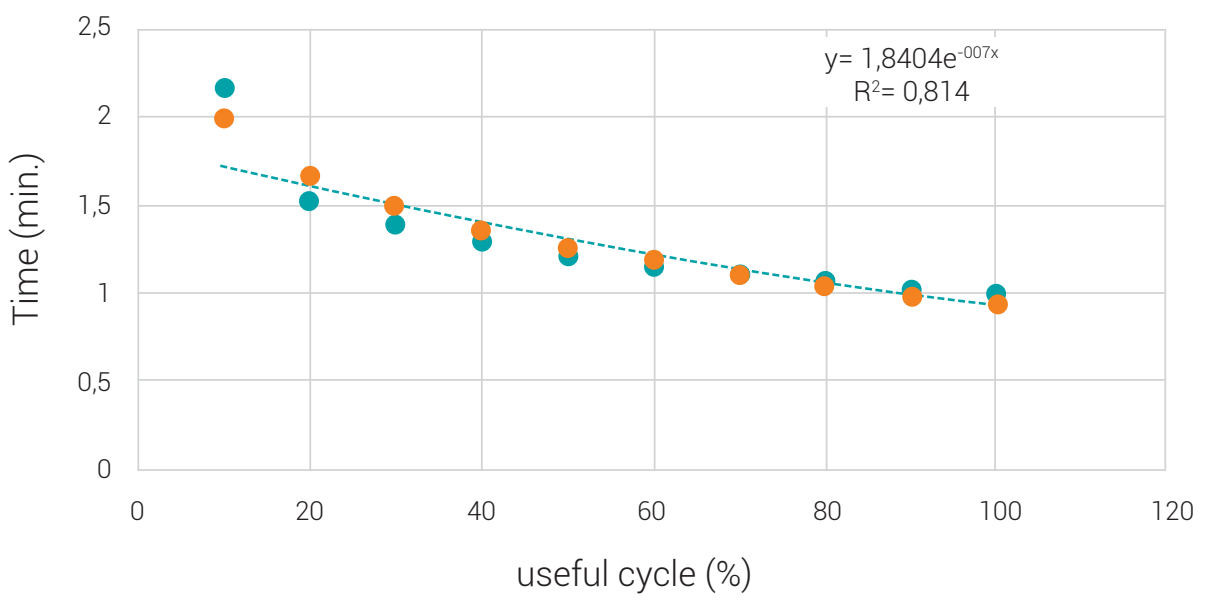

Figure 28. Graph of variation of time for pulse widths between 0 and $100 \%$. Source: own work.

As can be seen in Figure 28, as the value of the useful cycle is increased, the tank's filling time decreases exponentially, knowing that the inertia in useful cycle values exceeds $20 \%$ 
Flow with sensor SFI-800-1/2

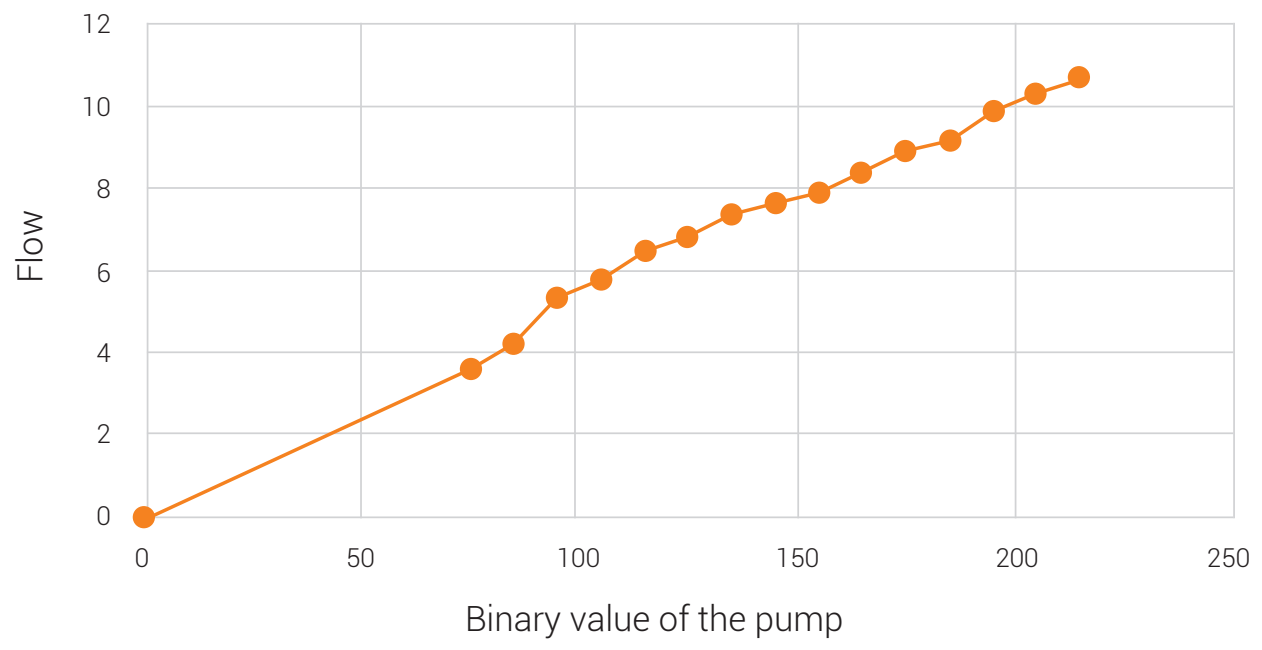

Figure 29. Graph of variation of flow for different binary values assigned to the pump. Source: own work.

Figure 29 shows the variation of the flow measured with a sensor SFI-800-1 / 2 , obtaining an increasing linear relationship with respect to the assigned useful cycle and it is observed that when exceeding the binary values corresponding to $20 \%$ the inertia is overcome.

Flow with sensor SFI-800-1/2

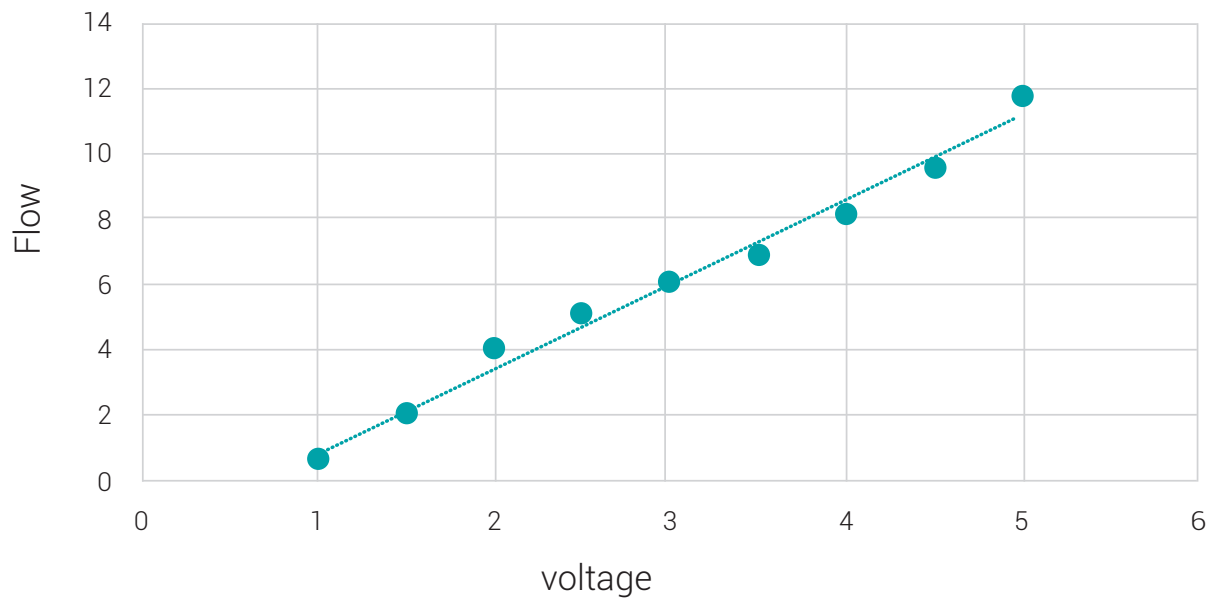

Figure 30. Graph of variation of flow for different analogous values assigned to the pump

Source: own work 
As in the variation with binary values, in Figure 30 the variation of the flow measured with a SFI-800-1 / 2 sensor is observed obtaining a linear increasing relationship with respect to the analogous values of the pump.

\section{Conclusion}

The present article has developed a design of an AD for hydraulic systems as an instrument that controls, in this investigation, the flow of an actuator type electric pump, which -by means of the power circuit- is responsible for supplying the liquid for the modules of a didactic plant. This actuator is a centrifugal DC pump of magnetic coupling, whose characteristics allow it to transport different liquids - without damaging the pump - up to 24 liters/minute - to a maximum relative height of 4.1 meters, according to the mathematical and physical modeling. This makes it possible to send the liquid to a high place efficiently. As the electric pump belongs to a multi-tank teaching system, the user has the ability to vary the magnitudes indicated digitally and analogously by means of two user interfaces designed for the Java PC and Labview ${ }^{\circledR}$. When developed in compliance with the IEEE 1451 standard, the intelligent actuator architecture is assimilated in blocks to a device composed of: a TCP / IP Network, NCAP, TIM, TEDS, Power module, Raspberry Pi Font, PSoC 4, NI data acquisition card, a PC, and the corresponding actuator or electric pump. The IEEE 1451 standard also regulates the adjustment of the design for a possible failure or de-calibration of the device for the support and its repair or replacement of components, ensuring the longevity of the device.

Acknowledgments: to the ORCA and SciBas research group, for the implementation and modeling, respectively, of the project implemented.

\section{References}

[1] Institute of electrical and Electronics Engineers, IEEE Taxonomy Version, vol. 1, pp. 1-67, 2014. [Online]. Available: www.ieee.org,

[2] A. Delgado, Ingenieria de Maquinas 'ACTUADORES HIDRÁULICOS', p. 15, 2013.

[3] J. P. Abriata, Instituto de energia y desarrollo ustentale, Una mirada a la conversión de la energía, p. 2, 2013. 
[4] S. Dalley and J. Oleson, Bomba hidráulica,. [Online]. Available: http://fluidos.eia.edu.co/, 2012.

[5] D. Lara, Bomba centrífuga,. [Online]. Available: http:/ / www. bombaindustrial. com/ Blog, 2012.

[6] Univ. Nac. Exp. Francisco De Miranda, Sistemas Hidráulicos - Bombas Hidráulicas, 2011.

[7] Universidad de Zalamanca, Sección 1: clasificación y tipos de bombas, [Online]. Available: http://cidta.usal.es/Cursos/redes/modulos/Libros/unidad 9/clasificacion.PDF.

[8] D. Garzón, J. López, y A. Escobar, Válvula inteligente actuador para sistemas hidráulicos. Universidad Distrital Francisco José de Caldas, 2015.

[9] S. M. Arango R., Desarrollo Del Sistema De Control De Nivel Para Un Tanque Surtidor De Agua Y Almacenador De Energía Térmica En Procesos De Lavado Y Tintoreria, pp. 1-63, 2008.

[10] D. Jethwa, R. R. Selmic, F. Figueroa, Real-Time Implementation of Intelligent Actuator Control with a Transducer Health Monitoring Capability, pp. 1441-1446, 2008.

[11] K. J. Anto, J. J, B. E, and S. N, “Raspberry Pi Based Liquid Flow Monitoring And Control," Int. J. Res. Eng. Technol., vol. 3, no. 07, pp. 123-125, 2014.

[12] P. Fernández D., Bombas centrífugas y volumétricas, Departamento de Ingeniería Eléctrica y Energética, Univerisda de Cantabria. [Online]. Available: http://www.termica.webhop.info/

[13] A. De Mar, A. De Oliva, A. Frio, M. Dura, y P. Especifico, Hidrostática Fuerza y presión, Fis. - CBC, pp. 1-11, 2013.

[14] Ingeniería Civil, Bombas de desplazamiento positivo, [Online]. Available: http://www.ingenierocivilinfo.com/2011/11/bombas-de-desplazamiento-positivo.html.

[15] Conceptos Basicos de Neumática e Hidráulica, [Online]. Available: http://www.sapiensman. com/neumatica/neumatica_hidraulica9-A.htm.

[16] Netzsch, Bombas lobulares TORNADO ${ }^{\circledR}$ - NETZSCH Bombas, [Online]. Available: https://bombas.netzsch.com/es/productos-soluciones/bombas-de-lobulares-tornado/

[17] How Pumping Systems Design Affects Sealing Performance | Flow Control Network, [Online]. Available: http://www.flowcontrolnetwork.com/how-pumping-systems-designaffects-sealing-performance/. 


\section{Alex Esteban Barbosa Torres, Andrés Escobar Díaz, Harold Vacca Gonzalez 29}

[18] P. Fernández, Bombas Centrífugas y Volumétricas. Universidad de Cantabria, 2012, p. 178.

[19] G. M. Reina, Manual para el diseño de una red hidráulica de climatización,. Universdad de Sevilla, 2012, p.39.

[20] H. E. Bohórquez A., Lección 22 Bombas Centrifugas, [Online]. Available: http://datateca.unad. edu.co/contenidos/211618/EXELARNING/leccin_22_bombas_centrifugas.html.

[21] DROTEC -bombas industriales-, Breve Introduccion a las Bombas de Acople Magnetio, Vol. 2, 2012, pp. 1-4. [Online]. Available: www.drotec.com.ar.

[22] PicoTechnology,SomepowerPWMdriversforDCelectricmotors,[Online].Available:https://www. picotech.com/library/application-note/some-power-pwm-drivers-for-electric-dc-motors.

[23] C. D. E. E., V. D. L. N., Sánchez, Control de motores de Corriente Continua-Puente en H., Guadalajara, pp. 1-6, 2011.

[24] SGS - Thomson Microelectronics, Applications of monolithic bridge drivers., 1995, pp. 1-11,

[25] Robots Argentina, Manejo de potencia para motores con el integrado L293D, [Online]. Available: http://robots-argentina.com.ar/MotorCC_L293D.htm.

[26] E. P. L. Co, DC Fan Speed Control, 2015. [Online]. Available: http://emant.com/80110.page.

[27] Texas Instruments, ULN200x, ULQ200x High-Voltage, High-Current Darlington Transistor Arrays Datasheet. , pp. 1-34.

[28] Arduino, Señales analógicas de salida en Arduino (PWM), [Online]. Available: http://playground.arduino.cc/ArduinoNotebookTraduccion/Appendix3.

[29] Pico Technology, Some power PWM drivers for electric DC motors, [Online]. Available: https:// www.picotech.com/library/application-note/some-power-pwm-drivers-for-electric-dcmo-tors, 2010. .

[30] F. Brissaud, A. Barros, C. Bérenguer, and D. Charpentier, "Reliability analysis for new technology-based transmitters," Reliab. Eng. Syst. Saf., vol. 96, no. 2, pp. 299-313, Feb. 2011.

[31] Network Capable Application Processor Interface Module Transducer Transducer Electronic Data Sheets Smart Transducer Services Web, pp. 5-28.

[32] J. F. Herrera-Cubides, P. A. Gaona-García, C. E. Montenegro-Marín, S. Sánchez-Alonso, y D. MartinMoncunill, "Abstraction of linked data’s world", Visión electrónica, vol. 13, no. 1, pp. 57-74, feb. 2019. https://doi.org/10.14483/22484728.14397 